\title{
The contribution of Project-based-learning to high-achievers' acquisition of technological knowledge and skills
}

\author{
David Mioduser · Nadav Betzer
}

Received: 27 August 2003/ Accepted: 12 July 2006/Published online: 4 January 2007

(C) Springer Science+Business Media B.V. 2006

\begin{abstract}
The main goals of this study were to look after the technological knowledge construction process by high-school high-achievers, and their ability to design and implement solutions for technological problems. More specifically, we examine the contribution of Project-based-learning (PBL), as pedagogical means for supporting the students' knowledge acquisition and problem-solving process. The findings show a significant increase in formal knowledge as measured by standardized matriculation exams; an expansion in the scope of technological knowledge acquired and implemented, and in the scope of knowledge resources utilized for the projects; a high level of overall performance as regards to the set of design skills studied; a positive change in attitude towards technology and technological studies; the emergence of consistent design styles by individuals and groups along their work in the projects.
\end{abstract}

Keywords Project-based learning · Design learning · Design styles · Technological knowledge $\cdot$ High-achievers

The number of high-school students who choose to learn technological education is decreasing consistently in many countries, including Israel. Moreover, most of the students in technology education tracks belong to the mid and low achievers amongst the high-school population. Both aspects - the decrease in number of students and the reticence of high achievers to learn technology—stand in contradiction with the demand imposed by the massive integration of current technologies in all areas of life (e.g., economy, security, health treatments and services, leisure culture, quality of life in general), for more technologically literate and knowledgeable citizens in one hand, and more professionally-trained human resources in the other.

D. Mioduser $(\bowtie)$

School of education, Tel Aviv University, Tel Aviv 69978, Israel

e-mail:miodu@post.tau.ac.il

N. Betzer

Science and Technology Administration, Ministry of Education, 2 Hashelosha Str., Tel Aviv 61092, Israel 
The actual challenge is therefore twofold: to ensure the acquisition of an appropriate technological knowledge base by the population at large, and at the same time to attract high-achievers to high-quality technological studies.

The study presented in this paper focuses on the second challenge, namely, the planning and implementation of technological studies for high-school high-achievers who learn in comprehensive schools (not in specialized technology-education programs). The main goals of the study were to examine the technological knowledge construction process by these students, and their ability to design and implement solutions for technological problems. More specifically, we examine the contribution of Project-based-learning (PBL), as pedagogical means for supporting the students' knowledge acquisition and problem-solving process.

\section{Background}

Countries face the above presented challenges and demands by devising policies and long-term plans, aiming to provide the required education to both the general population (in the form of Technological Literacy) and the expertise-seeking population (in the form of specialized studies) as part of their formal education (e.g., Del Valle, 1993; ITEA, 2000; Savery \& Duffy, 1995; Technology for all Americans, 1996; What Work Requires of Schools, 1991; Williams \& Williams, 1997). Immediate implications of these policies are: (a) the need to identify the expected cognitive and learning outcomes for the different populations of learners (Mioduser, 1998); and (b) the need to define in curricular and pedagogical terms the way to fulfill the stated goals (e.g., see Kimbell, 1997; Lewis, 1996; Verner \& Betzer, 2001; Williams, 2002). The following sections present the cognitive and pedagogical conceptual frameworks that served as background for our study.

\section{Cognitive aspects of technological problem-solving (TPS)}

As regards to the study of expected cognitive and learning outcomes, we rely in this study on a framework comprising two main components (Mioduser, 1998): the learning space (population level) and the cognitive architecture (individual level) of TPS.

The learning space is the frame within which actual learners-their cognitive goals, knowledge needs, and performance-can be situated. As such this represents an attempt to decompose the overly general definitions of "technological literacy" and "technological expertise" into more specific chunks of knowledge and skills according to the needs of different technology practitioners (e.g., a knowledgeable user, an amateur practitioner, or an expert). The result is a matrix allowing the mapping of a person's (or population subgroup) knowledge needs, cognitive goals, required skills, and the supposed internal (cognitive) representations of these resulting from the functional goal regarding TPS at each level of expertise.

The second component of the framework is the TPS Primitives repertoire. The primitives are the basic units or building blocks of the problem-solving process, classed into four categories: Rudiments, Mental Models, Methods and Metaknowledge. Rudiments are the basic building blocks of technology related performance. These may be single pieces of knowledge but they may also be chunks built out of these single pieces, composite units for solving technology-related problems. Rudiments include declarative knowledge (e.g., properties of materials, measurement 
units, types and functions of Lego building blocks), and procedural knowledge (e.g., how to operate a toaster oven, how to assemble Lego bricks, silk-screen printing). The problem solver's Mental Model of a target technological system or a problem situation is a key factor in the problem-solving process. In view of these models as primitives or resourceful units for problem solving, a number of crucial issues are considered: their structure, the methods by which they are constructed, the way they evolve, the way they are retrieved and used, the different kinds of models, and the correspondence between models' properties and individual differences among problem solvers (e.g., age level, level of expertise). Methods as primitives are the intellectual methodological tools serving TPS. The core methodological tool for TPS is the design-process, by which technological knowledge and products are generated in systematic ways. Additional methodological primitives are for example systematic data gathering and information retrieval methods, model building, troubleshooting, or debugging methods. Meta-level primitives concern the ways the learner uses primitives from the previous levels (e.g., rudiments, models, methods) and controls the problem-solving process. This may be referred to as the metacognitive layer of the TPS process.

\section{Project-based-learning (PBL) as pedagogical approach for teaching TPS}

Project-based-learning was suggested by many as promising pedagogical approach for teaching TPS (e.g., Albanese \& Mitchell, 1993; Blumenfeld et al., 1991; Vernon \& Blake, 1993; Williams \& Williams, 1997). With strong roots in constructivist theories (Savery \& Duffy, 1995), PBL engages the students as active agents in a learning process characterized by recurrent cycles of analysis and synthesis, action and reflection. In addition, it fits the characteristics of real-life TPS by technology practitioners (Resnik \& Ocko, 1990). In this respect, Middleton (2005) defines these as meaningful activities having "a contingent relationship with the real world that is both inside and outside of the classroom. That is, the ideas and processes that students engage with are connected to the lived world rather than being abstracted from it"..."the solutions students produce are real solutions from real materials" (pp. 67). The main pedagogical construct for implementing PBL in the classroom is the project, which may appear in various configurations from a singular activity lasting several weeks, to an evolving activity to be completed along the academic year or even 2 years (as described in Verner \& Betzer, 2001, or Ginestie, 2002). Briefly stated, PBL can be characterized as:

- A creative and branching process triggered by an authentic need or problem, leading towards a working solution.

- A progression of stages of varied nature required for the devise of the solution, e.g., accurate definition of the problem, and its solution requirements and constraints; generation of alternative solutions and their evaluation by defined criteria; model building.

- The demand for a wide array of skills related to different functions, e.g., information search and retrieval; representing ideas using formal notations; building physical models.

- The demand for collaborative work skills, e.g., distribution of functions according to expertise; parallel and cooperative work.

- Continuous evaluation of each stage's products and of the solution at all. 
Recent research examined different facets in the educational implementation of PBL, e.g., thinking patterns and processes by students dealing with complex projects (Blumenfeld et al., 1991); reflection and evaluation while designing (Williams \& Williams, 1997); decision making and generation of optimal solutions (Evensen \& Cindy, 2000); solution modification/evaluation cycles by students (Mioduser \& Kiperman, 2002); teamwork (Perrenet, Bouhuijs, \& Smits, 2000) and comparison between individual and collaborative design processes (Hill \& Howard, 1998); different curricular configurations of PBL (e.g., Edgerton, 1993; Ginestie, 2002; Litchfield, 1995; Verner \& Betzer, 2001; Williams, 2002). From all different perspectives, there is strong agreement as regards to the educational potential of PBL in technology education.

This study builds upon the above research, and examines closely a long-term learning process based on the adoption of PBL as main pedagogical solution for involving students in doing design. As an additional hypothesis, we assumed that PBL would prove suitable for attracting high-achievers (who are not students in technological strands) into high-level technology studies. The long-term examination focused on three main levels: knowledge acquired, cognitive processes elicited, and attitude changes. Correspondingly, our research questions were:

1. Do students' achievements (as regards to Machine Control concepts) increase as a result of their engagement in PBL and in comparison with students learning by traditional methods?

2. Does PBL affect students' technological knowledge usage patterns, design-skills acquisition and design performance?

3. Does PBL contribute to changes in students' attitudes towards technology (regarding issues such as technological studies, gender and technology, technology-related careers, social consequences of technology)?

\section{Method}

Population

One hundred and twenty students participated in the study, 60 in three experimental classes from comprehensive high schools, and 60 in three control classes from technological high schools. Experimental group students were defined as highachievers by their academic achievements. All students were entitled to take the Israeli matriculation exams.

\section{Instruments}

Five instruments served the data collection and analysis as regards to achievements, attitudes, and varied qualitative aspects of the design process.

Achievements and knowledge gain (research question no. 1) were measured using the standard exam on "Machine Control" commonly administered at the national level as matriculation exam. It was conducted prior to and after the learning process with both the experimental and the control groups. These exams are the product of a rigorous process of development, in practice since the early 90s. A three members 
committee develops each year's version of the exam based on the official syllabus, and explicit methodological guidelines (e.g., indication for each question and subquestion of the specific curricular concept or topic covered, or relative weight of the item within the whole exam). The exam is analyzed (and solved) by teachers/ examiners, and corrected if needed. This cycle is repeated until the version is completed. Following its administration, two independent examiners grade each student's exam, and if there are discrepancies of more than $14 \%$, a third (senior) examiner is requested to grade it. Finally, a longitudinal analysis is conducted relating the given year results to these of all previous years.

Students' attitude towards technology (research question no. 3) was examined prior and after learning using the Pupils' Attitudes Towards Technology (PATT) questionnaire (PATT, 1987).

Data on qualitative aspects of the design process by the students (research question no. 2) were collected and analyzed using three tools specifically developed for this study. Three independent judges carried out the content analysis of the data. Agreement of over $80 \%$ was set-and reached-as validity level for their judgments.

The first two tools were used to map the scope of knowledge and the sources of knowledge used by the students during the learning process. For this mapping, at each stage of the design process the students' products (e.g., drawings, designs, actual systems built) were analyzed in terms of knowledge items embedded. Each item was characterized by its content, and in addition was classed using two scales: the first (1-4) indicating the scope of the knowledge utilized (knowledge within the students' knowledge-space; knowledge defined in the specific learning materials; knowledge included in the formal curriculum; knowledge outside the curricular envelope); the second scale (1-5) indicating the source of the knowledge (personal knowledge; learning units; peers and experts; additional knowledge sources at hand; distant resources).

A third tool was implemented to evaluate the characteristics of the students' performance (in a 4 level scale) as regards to eight qualitative aspects of the design process: ability to identify a design-demanding situation; ability to implement appropriate technologies in the design; ability to choose appropriate materials for the design; ability to evaluate the design process and products; mastery of technological knowledge presented in the curricular materials; personal approach towards the design process; originality and creativity in generating design solutions; awareness of social and economic aspects of technological design. The definitions of the criteria applied for analyzing students' design performance are presented in Table 1.

In this paper, we have chosen to present the in-depth analysis of six projects (see projects description in next section).

\section{Learning process and procedure}

The contents and concepts studied by both groups pertain to the "Machine Control" curriculum for the High School, which is similar for both comprehensive and technological schools in Israel. The "Machine Control" discipline was developed in 1989 and implemented in 1990, as part of the technological education reform in Israel. This subject has been authorized and accredited by the Israeli universities as one of six main disciplines conferring additional benefit for admission purposes. Its main 


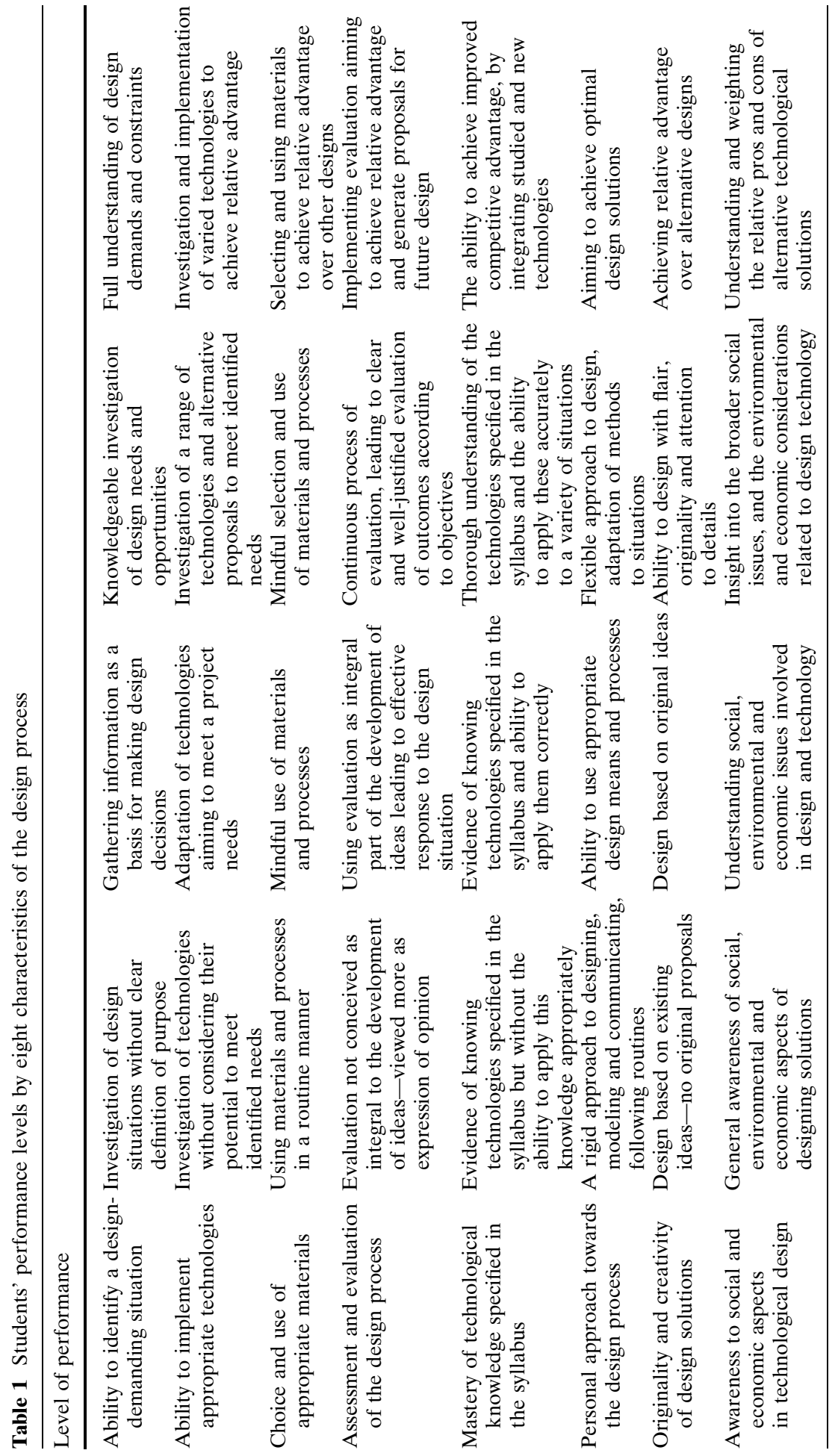


goals focuses on the development of systemic thinking, the acquisition of design knowledge and skills, the acquisition of scientific and mathematical background for the design of control systems, and the ability to implement control processes in typical technological systems. The main topics included in the learning unit in this study are shown in Table 2. Both the contents and instructional units, and the standard evaluation instruments, are coherently developed under the supervision of the Ministry's superintendence for the discipline.

The instructional process for the experimental group was devised as an integration of PBL and traditional learning methods (e.g., lectures, use of printed materials, homework). The course was delivered in three frontal hours and six PBL hours every week, over 2 years. The control group students were taught using only the traditional teaching methods implemented in technological schools, for six frontal hours every week, over 2 years.

At the center of the learning process stands an advanced design project the students were requested to plan and implement along the 11 and 12 year of study. These graduation projects are subject to external assessment by Ministry of Education's staff, and serve as substitute for the national exams of the "Machine Control" discipline.

In-depth analysis-examples from six projects

Six projects were selected for presentation in detail in this paper. Four were carried by the experimental group students: TNT programming team; RoboCandle, 2000 programming team; Electric motors; Climbing robot. Two were carried by the

Table 2 Course subjects and hours of instruction

\begin{tabular}{llr}
\hline & Subjects & Hours \\
\hline 1 & Basic Systems Concepts & 2 \\
1.1 & Introduction to Control & 2 \\
1.2 & Block Diagrams of System Components & 5 \\
1.3 & Open and Closed Control Loops & 4 \\
1.4 & Typical Control Processes & 10 \\
1.5 & Applications of Control Systems & 8 \\
1.6 & Steady-state Control Systems Response & 8 \\
1.7 & Dynamic Response of Control Systems & 4 \\
1.8 & Control System Stability & 9 \\
1.9 & Computerized Control System & 4 \\
2 & Logic and Automation & 7 \\
2.1 & Introduction to Automated Systems & 10 \\
2.2 & Physical Flows Features & 10 \\
2.3 & Power Sources & 5 \\
2.4 & Automation Devices and Components & 7 \\
2.5 & Overview of Binary and Analog Sensors & 14 \\
2.6 & Actuators & 10 \\
2.7 & Logic Concepts (Gates, Boolean functions, Carno Maps) \\
2.8 & Logic Circuits & 9 \\
2.9 & Applications of Logic in Controlled Systems & 22 \\
2.10 & Hydraulic and Pneumatic Systems & 150 \\
& Total Instruction Hours & \\
\hline
\end{tabular}


control group students: Worm transmission; Pool filter. In the following the projects are briefly described.

\section{Project No. 1}

Project name:

Project objective:

Project team:

Device's

objectives:

\section{TNT programming team}

Programming the robot towards a competition

Three members as sub team of the robot group

The autonomous robot was built especially towards a robot contest following obligatory rules. Still there was endless space for student decisions considering planning, building and programming the robot. The mission of the robot was to look for a fire inside an apartment model, extinguish the fire and return back to the home position. The team should devise a relative advantage in their program in order to win the competition.
Project No. 2

Project name:

Project objective:

Project team:

Device's objectives:
RoboCandle 2000 programming team

Programming the robot towards a competition

Two members as sub team of the robot group

The objective was the same as in the previous project.
Project No. 3

Project name:

Project objective:

Project team:

Task objectives:
Electrical motors with location and motion control

The creation of learning materials in the discipline

Two members as sub team of the robot group

Preparation of learning materials based on survey and study of the subject. The students were free to decide whether the project will be pure theoretical or both theoretical and experimental.

\section{Project No. 4}

Project name: Project objective: Project team: Robot objectives:
Hephaestus (the god of fire)—climbing robot

To plan and construct a vertical climbing robot

Two members

The project was initiated by two students from the experimental group (they had no former technological knowledge), looking for an intellectual-technological challenge in their last 2 years in school. The climbing robot project stood by itself without any relation to the robots competition.
Project No. 5

Project name:

Project team:

Device

objectives:

\section{Manual worm gear}

Knowing the system, its structure and operation principles

Two members

Manual worm gear transmission allows the students to learn about reduction principles. They are exposed to different production processes, and have the opportunity to see how the raw material is worked and machined from the idea to the finished product through all design stages. The project is part of the technological education curriculum and said to be of help for the acquisition of required knowledge. 
Project No. 6

Project name:

Project objective:

Project team:

Robot objectives:
Water cleaning and filtration for swimming pools

Design, planning and building an automatic water filtration system

Individual task

Water cleaning and filtration are necessary and continuous processes in swim ming pools. The student chose to design and construct a system which does the job automatically without the intervention of an operator. The idea was based on the pressure differential between water input and output to and from the filter. This project forces the student to expand his knowledge much beyond the compulsory curriculum. He should know about water treatment, sensors, logic and control means like Programmable Logical Controller (PLC) and Man Machine Interface (MMI).

\section{Findings}

Research question 1: Do students' achievements (as regards to Machine Control concepts) increase as a result of their engagement in PBL and in comparison with students learning by traditional methods?

The learning achievements of the students in both groups were measured by means of the standardized matriculation exam administered as pre and post-tests. The means for both groups, in both tests by gender appear in Table 3, Fig. 1. Students in both groups showed poor knowledge of the curricular concepts in the pre-test, as expected. While experimental group students (from a comprehensive school, without previous studies in technology) had almost no knowledge on the

Table 3 Pre and Post-test results by the experimental and control groups

\begin{tabular}{|c|c|c|c|c|c|c|}
\hline & \multicolumn{3}{|c|}{$\begin{array}{l}\text { Experimental group (comprehensive } \\
\text { classes) }\end{array}$} & \multicolumn{3}{|c|}{ Control group (technological classes) } \\
\hline & $\begin{array}{l}\text { Boys } \\
(N=31)\end{array}$ & $\begin{array}{l}\text { Girls } \\
(N=8)\end{array}$ & $\begin{array}{l}\text { Total } \\
(N=39)\end{array}$ & $\begin{array}{l}\text { Boys } \\
(N=56)\end{array}$ & $\begin{array}{l}\text { Girls } \\
(N=12)\end{array}$ & $\begin{array}{l}\text { Total } \\
(N=68)\end{array}$ \\
\hline Pre-test M (SD) & $2.55(3.85)$ & $0.63(1.77)$ & $1.59(3.59)$ & $23.98(16.36)$ & $21.33(10.23)$ & $22.66(15.42)$ \\
\hline Post-test M (SD) & $80.45(20.88)$ & $92.25(9.81)$ & $86.35(19.63$ & $73.21(14.18)$ & $76.25(16.25)$ & $74.73(14.48)$ \\
\hline
\end{tabular}

Fig. 1 Pre and post-test results for the experimental and control groups

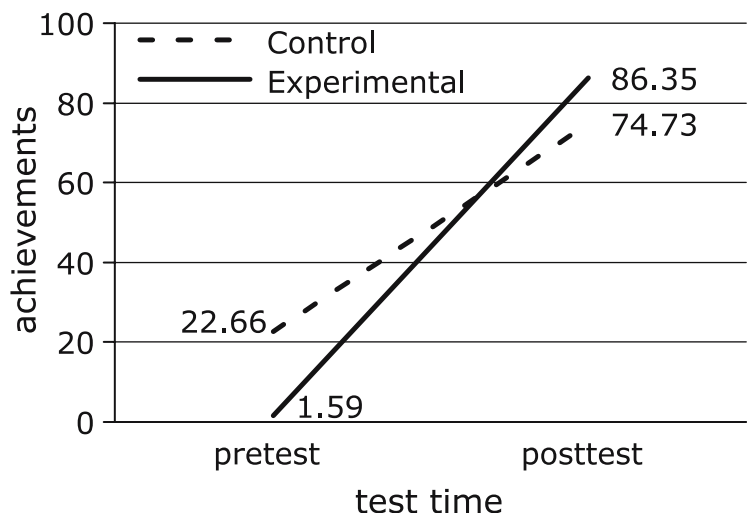


subject, technological school students showed about $20 \%$ of mastery of the concepts examined. After the learning process both groups performed significantly better, but the gain for the experimental group was impressive-an increase of $84 \%$ compared with $52 \%$ by the control group. The mean increase for the Girls of the experimental group was even higher, above $90 \%$.

Analysis of variance test considering the variables "group" (experimental, control), "testing-time" (pre, post) and gender showed significant difference for the gain in knowledge in both groups $(F(1)=754.67, P<0.01)$, and between groups $(F(1)=43.07, P<0.01)$, but not for gender.

It is evident from the above results that the instructional process in which the experimental group students were involved contributed clearly to their learning of machine control knowledge and skills. This evidence is even more significant if we consider that the students did not have any previous technological background and performed at the lowest possible level in the pre-test.

Research question 2: Does PBL affect students' technological knowledge usage patterns, design-skills acquisition and design performance?

As described in the method section, six groups (or projects) were selected for detailed qualitative data collection and analysis. The data was organized and analyzed as regards to four main issues: the first two relate to knowledge usage patterns, for which we looked at the scope and sources of the knowledge gathered and implemented; the third issue focuses on the development and activation of design skills; the fourth refers to the students' overall level of performance while working on the projects.

The analysis of the knowledge items embedded in the projects (Table 4) showed that the scope of knowledge used by students in the experimental group was wide and encompassed personal knowledge, knowledge included in the learning units used in class, and even a larger set of concepts pertaining to the formal syllabus of

Table 4 Knowledge usage by students in the experimental (E) and control (C) groups

\begin{tabular}{|c|c|c|c|c|c|c|}
\hline & \multirow{2}{*}{$\begin{array}{l}\text { Scope } \\
\text { of } \\
\text { knowledge* }\end{array}$} & \multicolumn{5}{|c|}{ Knowledge source** (by stage during the design process) } \\
\hline & & $\begin{array}{l}\text { Problem } \\
\text { identification }\end{array}$ & $\begin{array}{l}\text { Data } \\
\text { search } \\
\text { and } \\
\text { collection }\end{array}$ & $\begin{array}{l}\text { Generation } \\
\text { of } \\
\text { alternative } \\
\text { solutions }\end{array}$ & $\begin{array}{l}\text { Solutions } \\
\text { evaluation } \\
\text { and selection }\end{array}$ & $\begin{array}{l}\text { Solution } \\
\text { implementation }\end{array}$ \\
\hline E TNT & 3 & 5 & 5 & 5 & 5 & 5 \\
\hline E RoboCandle & 3 & 5 & 5 & 5 & 5 & 5 \\
\hline $\begin{array}{l}\text { E Electric } \\
\text { motor }\end{array}$ & 1 & 2 & 4 & 2 & 2 & - \\
\hline $\begin{array}{c}\text { E Climbing } \\
\text { robot }\end{array}$ & 3 & 4 & 4 & 5 & 4 & 4 \\
\hline $\begin{array}{l}\text { C Worm } \\
\text { transmission }\end{array}$ & 1 & 2 & 2 & 1 & 1 & 2 \\
\hline C Pool filter & 2 & 3 & 4 & 4 & 3 & 4 \\
\hline
\end{tabular}

* Scope of knowledge scale: (1) knowledge within the students' knowledge-space; (2) knowledge included in the learning materials; (3) knowledge included in the formal curriculum; (4) knowledge outside the curricular envelope

** Knowledge source scale: (1) personal knowledge; (2) learning units; (3) peers and experts; (4) additional knowledge from known sources; (5) distant resources

E) Springer 
the discipline. The boundaries of the knowledge embedded in the control group's projects were more limited, mostly up to topics presented in the learning materials used in class.

Similar observations were made along the design process regarding the sources for the knowledge used by the students. All students in the experimental group accessed knowledge from a varied range of sources beyond the information supplied in class or in the learning materials at hand. Searching for information in the Internet and approaching external resources (e.g., experts from universities) were integral to these students' knowledge-gathering activities. For example, the TNT programming team faced the problem of a systematic deviation in the designed straightforward motion of the robot. They decided to visit a technological institute and ask a researcher for help. The result of this collaboration with the expert was that they succeeded in working out a mathematical solution to the problem. In contrast, control group students used mostly information that was supplied in the learning materials used in class.

Design skills usage and acquisition was another important aspect of the study, for which observations were made all along the design process (Table 5). For example, the electric motor team used mainly previously known skills. They used mainly available knowledge, processing and editing it in common ways. On the other hand, the RoboCandle team developed and implemented specific new skills in almost each and every stage of the project, e.g., they planned and developed a task tree in a way which they never did in previous learning experiences; they learnt to imitate the robot's motion and activities in order to be more efficient in planning and programming it; they planned, developed and implemented experimental routines all along the work in the project. These and others were new skills sets developed and activated by the participating students.

The fourth aspect comprised in this research question relates to the overall performance of the students (Table 6). Looking at the data it is evident that there were teams that performed at a very high level all along the project stages, and other that showed poor performance.

Table 5 Skills acquisition by the experimental (E) and control (C) groups

\begin{tabular}{|c|c|c|c|c|c|c|}
\hline & & \multicolumn{5}{|c|}{ Skills use and acquisition } \\
\hline & & $\begin{array}{l}\text { Ability to } \\
\text { identify a } \\
\text { design- } \\
\text { demanding } \\
\text { situation }\end{array}$ & $\begin{array}{l}\text { Ability to } \\
\text { implement } \\
\text { appropriate } \\
\text { technologies }\end{array}$ & $\begin{array}{l}\text { Choice and use } \\
\text { of appropriate } \\
\text { materials }\end{array}$ & $\begin{array}{l}\text { Assessment and } \\
\text { evaluation of the } \\
\text { design process }\end{array}$ & $\begin{array}{l}\text { Originality and } \\
\text { creativity of } \\
\text { design solutions }\end{array}$ \\
\hline $\mathrm{E}$ & TNT & 4 & 4 & 4 & 3 & 4 \\
\hline $\mathrm{E}$ & RoboCandle & 4 & 4 & 4 & 4 & 4 \\
\hline $\mathrm{E}$ & Electric motor & 2 & 2 & 1 & 1 & 1 \\
\hline & Climbing robot & 4 & 3 & 3 & 4 & 4 \\
\hline $\mathrm{C}$ & $\begin{array}{l}\text { Worm } \\
\text { transmission }\end{array}$ & 1 & 1 & 2 & 2 & 1 \\
\hline & Pool filter & 3 & 3 & 3 & 3 & 3 \\
\hline
\end{tabular}

Scope of skills use and resources scale: (1) use of known skills; (2) development of new skills; (3) learning of new skills from peers and experts; (4) search for, retrieval and learning of new skills from different sources 
Table 6 Design performance by students in the experimental (E) and control (C) groups

\begin{tabular}{llllll}
\hline & \multicolumn{4}{l}{ Design performance* (by stage during the design process) } \\
\cline { 2 - 6 } & $\begin{array}{l}\text { Problem } \\
\text { identification }\end{array}$ & $\begin{array}{l}\text { Data search } \\
\text { and collection }\end{array}$ & $\begin{array}{l}\text { Generation of } \\
\text { alternative } \\
\text { solutions }\end{array}$ & $\begin{array}{l}\text { Solutions } \\
\text { evaluation } \\
\text { and selection }\end{array}$ & $\begin{array}{l}\text { Solution } \\
\text { implementation }\end{array}$ \\
\hline E TNT & 4 & 4 & 4 & 4 & 4 \\
E RoboCandle & 4 & 4 & 4 & 4 & 4 \\
E Electric motor & 1 & 3 & 1 & 1 & - \\
E Climbing robot & 4 & 4 & 4 & 4 & 3 \\
C Worm transmission & 1 & 2 & 1 & 1 & 2 \\
C Pool filter & 3 & 3 & 4 & 3 & 4
\end{tabular}

* Design Performance scale: (1) poor performance; (2) within curricular goals; (3) beyond curricular goals; (4) advanced performance

An example of high level performance, and outstandingly creative as well, is the design process by the "climbing robot" group. Their robot was equipped with vacuum catchers by which the device climbed up the wall. They observed that occasionally, due to irregularities in the wall surface, the vacuum catcher could not function properly and the robot could not continue the climbing. The students' solution (hardware and software as well) was to add the possibility for the device to make side displacements, thus overcoming the irregular obstacle. A schematic description of the solution, and its algorithm, are described in Figs. 2, 3. Basically, the robot will go forward until an obstacle is sensed; in that case an aside displacement is implemented until efficient catch is reached; the robot can continue now climbing up.

Another view on the differences in performance level of the observed groups is presented in Fig. 4. The graph represents the profile of performance of two groups, at the different design skills probed. We have chosen deliberately groups that performed at the highest and lowest level, to emphasize the profile differences. As regards to particular skills, we can see that evident differences in level of performance were observed for skills related to the personal stance towards the design of technological solutions: the personal approach towards the process, the ability to recognize a design-demanding situation, and the level of creativity and originality of the chosen solution paths. Less extreme but evident as well were differences in skills related to the perception and evaluation of the actual solution generation process: awareness to social and economical aspects, ability to implement appropriate technologies in the specific context, ability to assess and evaluate the design process and outcomes. The closest level of performance among the groups observed in relation to practical aspects, which were explicitly part of the courses syllabus: skills related to the implementation of specific technologies or the choice and use of materials. Overall, we want to stress here the consistency in level-of-performance over all skills, resulting in a clearly defined profile either at the highest or lowest level. We have chosen here to present two extreme profiles, but the consistency that characterizes them was observed for all groups analyzed as well (we will elaborate on this observation in the discussion section).

Research question 3: Does PBL contribute to changes in students' attitudes towards technology (regarding issues such as technological studies, gender and technology, technology-related careers, social consequences of technology)? 


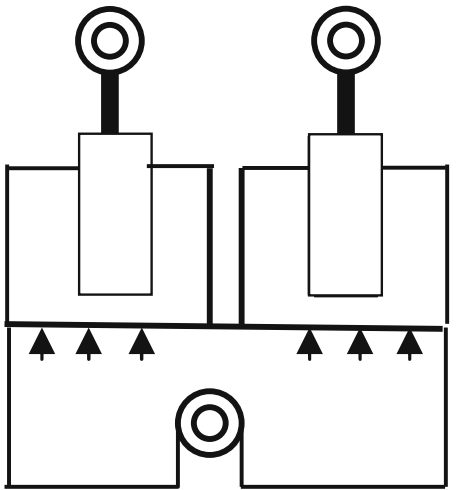

1. Initial position

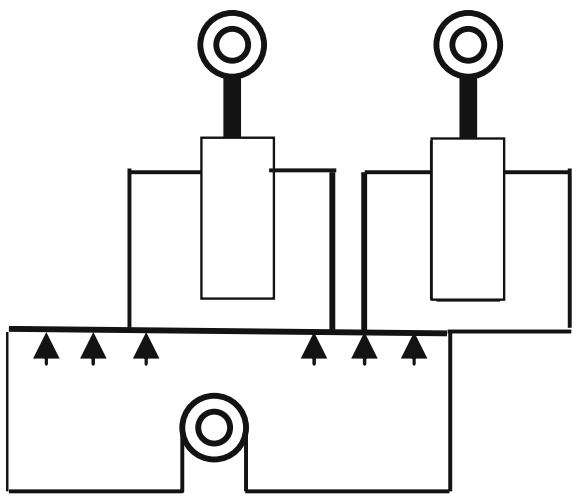

3. Second step to the right

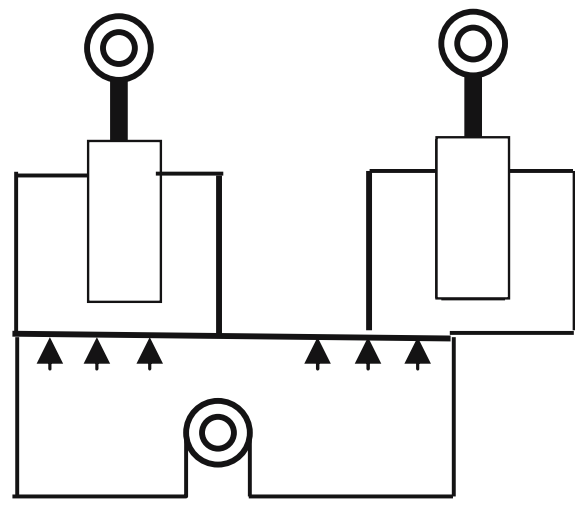

2. First step to the right

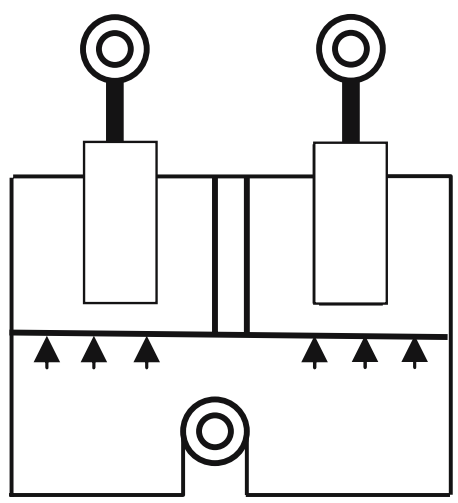

4. Completing right side motion

Fig. 2 Aside displacement routines of the "climbing robot"

The third research question is highly relevant for one of the contextual issues that motivated this study, namely, the reticence of most students, and high achievers among them, to enroll in technological courses. Motivation and attitudes were examined with both participant groups before and after the learning process. The results for both groups in both tests are presented in Table 7.

The data shows significant difference as regards to attitude towards technology between the experimental and control groups after the learning process $(F=6.54$, $P<0.05)$. In addition, significant and positive change in attitude between the pre and post-test was observed for the participants in the experimental group, but not for the control group (interaction between test-time/group, $F=10.69, P<0.01$ ). The interaction among test-time/group/gender at the significant level $(F=3.90, P<0.05)$ supports the observation that the female students in the experimental group showed clear positive change in their attitude towards technology, above the mean attitude level of their peers in the control group (post-test mean for female students in the experimental group was 3.24, and in the control group for female students 2.82 and male students 2.91).

Overall, the findings regarding students' attitude towards technology at the different perspectives probed (e.g., motivation, career, gender-based issues, social 


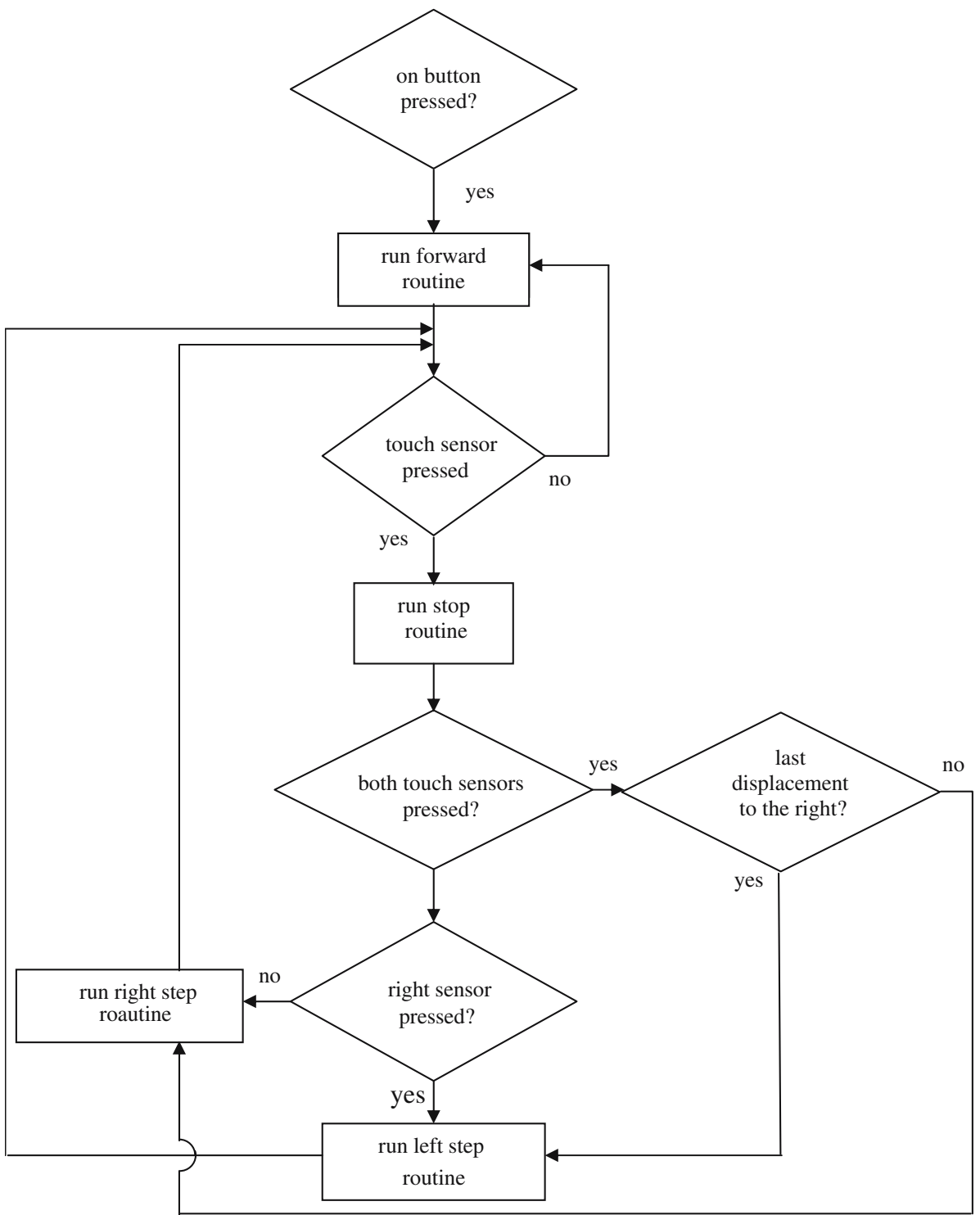

Fig. 3 General flowchart for the "climbing robot's" control algorithm

implications) indicate that the experimental group students, for whom the participation in the project was their first systematic learning encounter with technological content, developed a positive approach and perception of the essence and importance of technology. It should be noted that the control groups are regular technology students, who learn the subject by choice and for several years. These students' attitude towards technology is embedded in their selection of learning strand, and was not affected by the observed activity. In contrast, for the experimental group students, this was their first opportunity to be engaged in serious and 


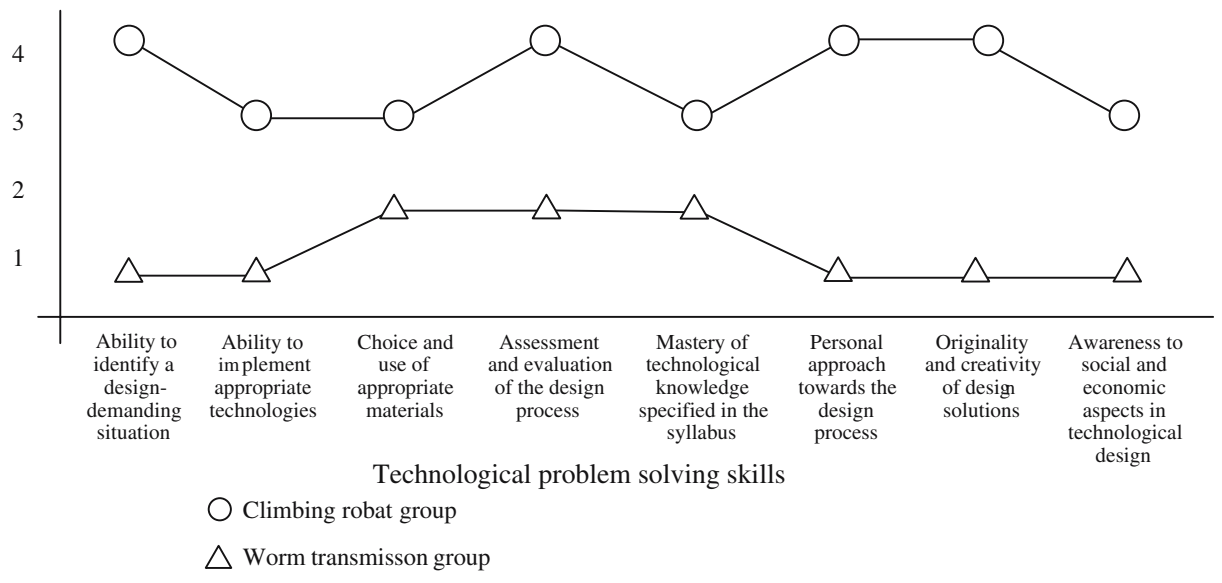

Fig. 4 Level of performance in technological problem solving skills

continuous manner over time in technological studies, implying also that they have not had previously the motivation to choose technology as a field to study. PBL highly motivating for them and a significant change in attitude was observed between the two measurement times.

\section{Discussion}

The study reported in this paper aimed to examine the technological knowledgeconstruction and problem-solving processes by high-school high-achievers who learn in comprehensive schools (not in specialized technology-education programs). Most of these students do not choose regularly to take technological subjects. In this study these students were offered the opportunity to be engaged in long-term projectbased learning tasks (PBL), challenging their motivation and academic abilities. The results, within the group and in comparison with a control group of technology students, were highly encouraging. In this section we discuss several salient features of the learning process, and elaborate on the educational implications of the study results.

The first observation relates, in simply and plain way, to the extent to which PBL contributed to the learning of curricular knowledge. The results indicate an impressive gain in knowledge for the experimental group students, from almost no knowledge at all in the pre-test to a high achievement level in the post-test. These results are more remarkable considering that the test used was the regular external

Table 7 Pre and Post-test results for attitude towards technology

\begin{tabular}{|c|c|c|c|c|c|c|}
\hline & \multicolumn{3}{|c|}{ Experimental group } & \multicolumn{3}{|c|}{ Control group } \\
\hline & Male & Female & Total & Male & Female & Total \\
\hline \multirow[t]{2}{*}{ Pre-test } & $2.98(0.30)$ & $2.87(0.43)$ & $2.92(0.32)$ & $2.93(0.32)$ & $2.98(0.24)$ & $2.96(0.31)$ \\
\hline & $N=38$ & $N=9$ & $N=47$ & $N=57$ & $N=9$ & $N=66$ \\
\hline \multirow[t]{2}{*}{ Post-test } & $3.08(0.27)$ & $3.24(0.19)$ & $3.16(0.26)$ & $2.91(0.28)$ & $2.82(0.23)$ & $2.86(0.27)$ \\
\hline & $N=42$ & $N=8$ & $N=50$ & $N=50$ & $N=18$ & $N=63$ \\
\hline
\end{tabular}


matriculation exam for the subject, which normally the students are prepared for in traditional instructional methods (e.g., frontal instruction, textbook tasks, organized curricular materials). The students in the experimental group implemented various strategies for knowledge gathering and organization, and from various sources beyond the curricular materials. It is evident that even in such an (apparently) ill structured and open ended process (in comparison with the one elicited by curricular materials and textbooks), the scope and resources of the knowledge reached by the experimental group students led to a similar level of formal knowledge (and even to a greater increase over the initial baseline) than that achieved by students with traditional instruction.

Besides the gain in formal knowledge, we found that PBL contributed to the experimental group students' meaningful learning in additional aspects as well: The students considerably expanded and enlarged their technological knowledge base; they improved their technological skills and acquired teamwork abilities; the technological design process was learnt and developed to significantly high levels; and as manifested by the participants themselves in questionnaires and interviews, it was for them a very surprising and enjoyable process of learning and doing technology. The students' positive attitudes towards technology improved to a large extent, with the main differences taking place among the female students. These findings support the claim that lack of knowledge about technological concepts, processes and skills, and lack of motivating learning situations as well, lead to misleading perceptions and actually to students refrain to choose technological subjects.

\section{Design styles}

An attempt to integrate our observations of the different aspects of the design process (as described in the findings for research question 2, i.e., knowledge scope and sources, design skills acquisition and implementation, and overall design performance level) supports the definition of different design styles implemented by the students during their work on the projects. These styles can be defined upon the criterion of consistency in the students' strategies and performance at the different stages of the design process. A schematic representation of the variations in strategy is depicted in Fig. 5. From the very first stage, students addressed the design process using different approaches, e.g., performing either a broad and open-ended or a highly focused research on the subject, or choosing to examine either a known solution or an open base of alternative solutions. Yet entering the conceptual design stage three main patterns of work were recognized, from a fairly structured linear process, via a branching-cyclical process, to a systemic process. These patterns were consistent along the different stages of the groups' work, characterizing the decision making, planning and solution-production performance of the students both at the individual and the team level as well. It is evident that this interesting issue raising from our observations of six teams, well deserves further research particularly at the individual level, focusing on cognitive features that could be associated to the emergence and implementation of the different design styles.

\section{Concluding remarks}

We would like to conclude with a few remarks regarding the implications of this study for technology education. The first relates to the students' attitudes towards 


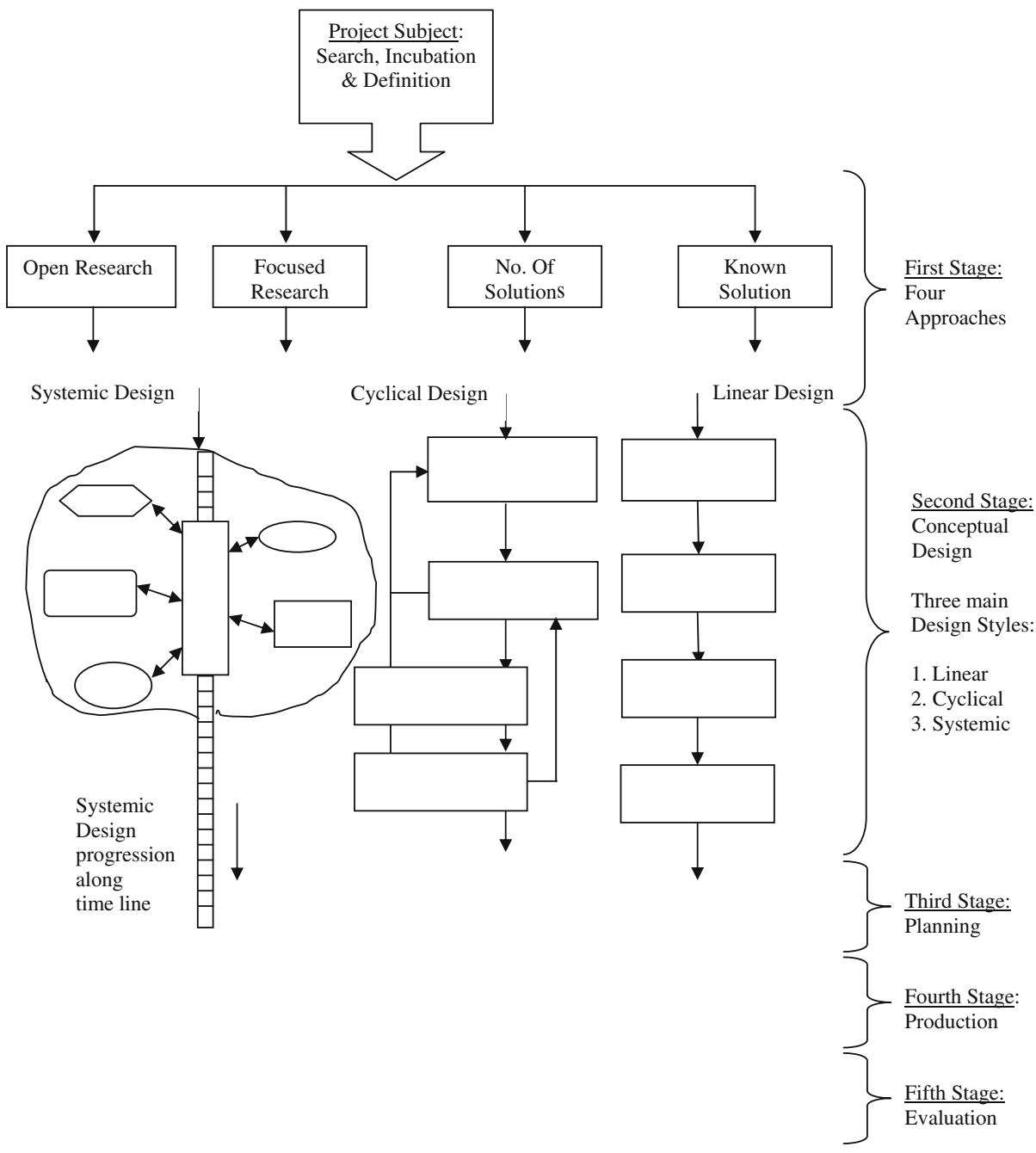

Fig. 5 Design styles implemented by the participant groups

technological studies. We have already mentioned that comprehensive school students with high learning achievements hold biased attitudes towards technology, which constitute a real barrier preventing them from studying the subject. As the results of this study indicate, it is evident that a learning proposal that represent a motivational and challenging opportunity for high achievers may contribute to overcome this barrier. The sophistication of the concepts and projects faced, together with the learning affordances of the instructional setting (PBL), supported the students long-term engagement in the projects.

PBL also proved to be a powerful instructional model allowing students to reach high learning achievements also at the expected formal knowledge level (and not only about in-depth knowledge related to each group's project topic). As implemented in this study, the integration of PBL and formal instruction sessions appears to be an appropriate curricular model for the learning of both the formal and the 
practical aspects of the generation process of a sound solution for a technological problem.

Last but not least, educators' awareness of different design styles by different students may undoubtedly contribute to adapt the instruction to the needs and perceptions of individual students and groups. We should take in account that engagement in PBL is a long-term process at which knowledge and skills are gradually acquired, the systemic perception of the design of technological solutions gradually evolves, as the consolidation of design strategies and styles as well. The instructional companion of this long-term process should be sensitive to both the development of, and the variation in, these personal and group styles.

It is obvious that more research is needed along the lines adopted in this study, but it is at the same time evident from it that in both quantitative (e.g., achievements, scope of knowledge) and qualitative (e.g., complexity of the projects, design skills acquired) terms PBL clearly contributed to high-school high-achievers meaningful learning of technology.

\section{References}

Albanese, M. A., \& Mitchell, S. (1993). Problem-based learning: A review of literature on its outcomes and implementation issues. Academic Medicine, 68(1), 52-81.

Blumenfeld, P., Soloway, E., Marx, R., Krajcik, J., Guzdial, M., \& Palincsar, A. (1991). Motivating project-based learning: Sustaining the doing, supporting the learning. Educational Psychologist, 26, 369-398.

Del Valle, C. (1993). The Workplace. Business Week, April 26, pp. 77-78.

Edgerton, R. (1993). Apply the curriculum standards with project questions. The Mathematics Teacher, 86(8), 686-689.

Evensen, D., \& Cindy, H. (Eds.) (2000). Problem-based learning: A research perspective on learning interactions. New Jersey: Lawrence Erlbaum Associates.

Ginestie, J. (2002). The industrial project method in French industry and in French schools. International Journal of Technology and Design Education, 12(2), 99-122.

Hill, A., \& Howard, A. (1998). Practice meets theory in technology education: A case of authentic learning in the high school setting. Journal of Technology Education, 9(2), 29-45.

International Technology Education Association (2000). Standards for technological literacy: Content for the study of technology. Virginia: Reston.

Kimbell, R. (1997). Assessing technology. International trends in curriculum and assessment. Buckingham: Open University Press, pp. 227-241.

Litchfield, B. (1995). Helping your students plan computer projects. The Computing Teacher, April, $37-43$.

Lewis, T. (1996). Comparing technology education in the US and UK. International Journal of Technology and Design Education, 6(3), 221-238.

Middleton, H. (2005). Creative thinking, values and design and technology education. International Journal of Technology and Design Education, 15(2), 61-71.

Mioduser, D. (1998). Framework for the study of the cognitive nature and architecture of technological problem solving. Journal of Technology Education and Design, 8(2), 167-184.

Mioduser, D., \& Kipperman, D. (2002). Evaluation/modification cycles in junior high students' technological problem solving. Journal of Technology Education and Design, 12, 123-138.

PATT - Pupils' Attitude Towards Technology (1987). In: R. C. Coenen-van den Bergh (Ed.), Report PATT-conference, cip-Gegevens Koninklijke Bibliotheek, Den Haag.

Perrenet, J. C., Bouhuijs, P. A. J., \& Smits, J. G. M. M. (2000). The suitability of problem-based learning for engineering education: Theory and practice. Teaching in Higher Education, 5(3), 345-358.

Resnik, M., \& Ocko, S. (1990). Constructionist learning. LEGO/LOGO: Learning through and about design. Boston: MIT Media Laboratory. 
Savery, J. R., \& Duffy, T. M. (1995). Problem based learning: An industrial model and its constructivist framework. Educational Technology, September-October, 31-37.

Technology for all Americans Project (TAAP) (1996). Reston, VA: ITEA.

Verner, I., \& Betzer, N. (2001). Machine control - a design and technology discipline in Israel's senior high schools. International Journal of Technology and Design Education, 11(3), 263-272.

Vernon, D. T., \& Blake, R. L. (1993). Does problem-based learning work? A meta-analysis of evaluation research. Academic Medicine, 68(7), 550-563.

What Work Requires of Schools, A SCANS Report for America 2000 (1991). Secretary's Commission on Achieving Necessary Skills - SCANS, Department of labor, Washington.

Williams, J. (2002). Design: The only methodology of technology? Journal of Technology Education, $11(2), 48-60$.

Williams, A., \& Williams, J. (1997). Problem-based learning: An appropriate methodology for technology education. Research in Science \& Technological Education, 15(1), 91-103. 